\title{
Traumatic Stress Induces Prolonged Aggression Increase through Synaptic Potentiation in the Medial Amygdala Circuits
}

\author{
(D)Jacob Nordman, ${ }^{1,2}$ ¿Xiaoyu $\mathrm{Ma}^{1}{ }^{1}$ and ${ }^{-}$Zheng Li ${ }^{1}$
}

https://doi.org/10.1523/ENEURO.0147-20.2020

${ }^{1}$ Section on Synapse Development and Plasticity, National Institute of Mental Health, National Institutes of Health, Bethesda, MD 20892, and ${ }^{2}$ National Institute of General Medical Sciences, National Institute of Health, Bethesda, MD 20892

\begin{abstract}
Traumatic stress can lead to heightened aggression which may be a symptom of psychiatric diseases such as PTSD and intermittent explosive disorder. The medial amygdala (MeA) is an evolutionarily conserved subnucleus of the amygdala that regulates attack behavior and behavioral responses to stressors. The precise contribution of the MeA in traumatic stress-induced aggression, however, requires further elucidation. In this study, we used foot shock to induce traumatic stress in mice and examine the mechanisms of prolonged aggression increase associated with it. Foot shock causes a prolonged increase in aggression that lasts at least one week. In vivo electrophysiological recordings revealed that foot shock induces potentiation of synapses formed between the MeA and the ventromedial hypothalamus $(\mathrm{VmH})$ and bed nucleus of the stria terminalis (BNST). This synaptic potentiation lasts at least one week. Induction of synaptic depotentiation with low-frequency photostimulation (LFPS) immediately after foot shock suppresses the prolonged aggression increase without affecting non-aggressive social behavior, anxiety-like and depression-like behaviors, or fear learning. These results show that potentiation of the MeA-VmH and MeA-BNST circuits is essential for traumatic stress to cause a prolonged increase in aggression. These circuits may be potential targets for the development of therapeutic strategies to treat the aggression symptom associated with psychiatric diseases.
\end{abstract}

Key words: aggression; medial amygdala; PTSD; synaptic plasticity; traumatic stress

\section{Significance Statement}

Heightened aggression can be a blight on society and a symptom of many psychiatric diseases. In this study we show that traumatic stress produces an enhancement of aggression that lasts at least one week through potentiation of synapses between the medial amygdala (MeA) and the ventromedial hypothalamus $(\mathrm{VmH})$ and bed nucleus of the stria terminalis (BNST). Depotentiation of these pathways immediately after foot shock suppresses the increase in aggression, while having no effect on anxiety-like, depressive-like, or non-aggressive social behaviors. This study identifies the MeA-VmH and MeA-BNST circuits and synaptic potentiation as neural substrates for traumatic stress-induced prolonged aggression increase and potential therapeutic targets in treating the aggression symptom of psychiatric illnesses such as PTSD.

\section{Introduction}

Aggression is an evolutionarily adaptive behavior to protect oneself from harm and acquire resources for survival (Nelson and Trainor, 2007). However, increased and abnormal forms of aggression can be harmful and may be

Received April 9, 2020; accepted June 17, 2020; First published July 10, 2020. The authors declare no competing financial interests. symptomatic of psychiatric disorders, including PTSD, antisocial personality disorder, borderline personality disorder, and bipolar disorder (Miczek et al., 2004, 2013; Nelson, 2006; American Psychiatric Association, 2013;

Author contributions: J.N. and Z.L. designed research; J.N., X.M., and Z.L. performed research; J.N. and Z.L. analyzed data; J.N. and Z.L. wrote the paper. 
Dorfman et al., 2014). Aggression can be influenced by prior agonistic and stressful experience. For example, in rodents, stressful life experience such as social deprivation can instigate unprovoked attack behavior, and this effect is exacerbated by traumatic stress induced by foot shock (Veenema, 2009; Toth et al., 2011; Chang et al., 2015, 2018; Zelikowsky et al., 2018; Chang and Gean, 2019). In humans, traumatic stress may trigger acute stress disorder and PTSD, and individuals with PTSD may exhibit increased aggression that lasts for years after the initial stressor (Nelson and Trainor, 2007; McHugh et al., 2012; American Psychiatric Association, 2013; Smerin et al., 2016; Taft et al., 2017). The neural circuits involved in traumatic stress-induced, prolonged aggression increase are largely unclear.

The medial amygdala (MeA), a subnucleus of the amygdala, is a key structure involved in social behaviors including aggression and behavioral responses to stressors (Rodgers, 1977; Müller and Fendt, 2006; Nelson and Trainor, 2007; Takahashi et al., 2007; Hong et al., 2014; McCue et al., 2014). The MeA is activated by attack behavior and traumatic stress, and its overaction is associated with abnormal displays of aggression (Potegal et al., 1996a,b; Rosen et al., 1998; Haller et al., 2006; Márquez et al., 2013; Hong et al., 2014). Stimulation of the MeA increases the likelihood of a future attack and modulates such behavioral responses to threats as risk assessment and defensive behaviors (Potegal et al., 1996a; Miller et al., 2019). Injection of serotonin into the MeA suppresses foot shock-induced aggression (Rodgers, 1977). Inhibition of MeA activity interferes with the processing of social cues to associate environmental cues with threats, and lesioning of the MeA suppresses fear responses to predator odors and decreases avoidance of physical stressors (Müller and Fendt, 2006; Takahashi et al., 2007; McCue et al., 2014; Twining et al., 2017). Notably, in humans the MeA is a successful neurosurgical target in the treatment of intractable escalated aggression (Mpakopoulou et al., 2008).

Neurons in the MeA project to multiple brain regions that influence aggressive behavior including the ventromedial hypothalamus $(\mathrm{VmH})$, bed nucleus of the stria terminalis (BNST), and lateral septum (LS; Gomez and Newman, 1992; Canteras et al., 1995; Coolen and Wood, 1998; Haller et al., 2006; Nelson and Trainor, 2007; Hashikawa et al., 2016). $\mathrm{VmH}$ activation is predictive of future attacks and optogenetic activation of the $\mathrm{VmH}$ promotes intermale aggression while optogenetic inhibition

This work was supported by the Intramural Research Program of National Institute of Mental Health Grant 1Z1AMH002881 (to Z.L.) and the National Institute of General Medical Sciences Postdoctoral Research Associate Training (PRAT) Program Grant 1FI2GM119962-01 (to J.N.).

Acknowledgements: We thank Daniel Letchford, Lindsay Ejoh, Princess Miranda, and Winnie Gao for analysis of behavioral data.

Correspondence should be addressed to Zheng Li at lizheng2@mail.nih.gov. https://doi.org/10.1523/ENEURO.0147-20.2020 Copyright @ 2020 Nordman et al.

This is an open-access article distributed under the terms of the Creative Commons Attribution 4.0 International license, which permits unrestricted use, distribution and reproduction in any medium provided that the original work is properly attributed. suppresses it (Kruk et al., 1983; Lammers et al., 1988; Lin et al., 2011; Yang et al., 2013; Falkner et al., 2014; Lee et al., 2014). The BNST is also activated by attack, and activation of the BNST modulates attack behavior in cats and increases social and attack behavior against conspecifics in mice (Masugi-Tokita et al., 2016). Hyperaggressive animals show low LS activity, inactivation or lesioning of LS promotes aggressivity, and optogenetic and electrical stimulation of LS suppresses it (Siegel and Skog, 1970; Albert and Wong, 1978; Ramirez et al., 1988; Goodson et al., 2005; Wong et al., 2016). All three areas are activated by stress, and the $\mathrm{VmH}$ and BNST have been shown to regulate aggressive responses to perceived threats (Silva et al., 2013; Anthony et al., 2014; Butler et al., 2015; Miller et al., 2019). The $\mathrm{VmH}$ in particular mediates the acute increase in aggression after foot shock (Chang and Gean, 2019). Based on these findings, it is intriguing to test whether these MeA target areas are involved in traumatic stress-induced prolonged aggression increase.

Here, using a combination of in vivo electrophysiology and optogenetics, we show that traumatic stress-induced by foot shock causes an increase in aggression and potentiation of synapses between the $\mathrm{MeA}$ and the $\mathrm{VmH}$ and BNST. These effects last for at least one week and can be abolished by synaptic depotentiation induced by low-frequency photostimulation (LFPS) of the MeA. These results indicate that traumatic stress drives prolonged increases in aggression through potentiation of select MeA pathways and suggest potential targets in the treatment of increased aggression associated with traumatic stress.

\section{Materials and Methods}

\section{Animals}

All animal protocols were approved by the Animal Care and Use Committee of the National Institute of Mental Health (ACUC). C57BL/6 male mice were purchased from Charles River. We housed mice under a $12 \mathrm{~h}$ light (9 P.M. to 9 A.M.)/12 h dark (9 A.M. to 9 P.M.) cycle with ad libitum access to water and food to be able to perform behavioral testing during the day, as this is the mice's dark phase when they are most active (Koolhaas et al., 2013).

\section{Surgery}

Ten-week-old mice were used for viral injection alone and seven-week old mice were used for viral injection followed by optrode implantation. Mice were anaesthetized with isofluorane $3 \%$ for induction and $1 \%$ for maintenance) and then placed onto a stereotaxic frame (David Kopf Instruments). Bilateral craniotomy was made and $500 \mathrm{nl}$ virus was injected into the MeA (AP: $-1.50 \mathrm{~mm}$; ML: $\pm 2.1 \mathrm{~mm}$; DV: $-5.15 \mathrm{~mm}$ ) using a $5-\mu \mathrm{l}$ gas-tight Hamilton syringe (33-gauge, beveled needle) at a rate of $0.1 \mu \mathrm{l} / \mathrm{min}$. After injection, the needle was left in place for an additional $5 \mathrm{~min}$ and then slowly withdrawn. Immediately after viral injection, ferrule-terminated optical fibers $(100 \mu \mathrm{m}$ in diameter, ThorLabs) were placed $100 \mu \mathrm{m}$ above the viral injection site at the MeA or at a midline position above the $\mathrm{VmH}$ (AP: $+1.5 \mathrm{~mm}$; ML: 0 
$\mathrm{mm}$; DV: $-5.7 \mathrm{~mm}$ ), BNST (AP: $+0.14 \mathrm{~mm}$; ML: $0 \mathrm{~mm}$; DV: $-3.8 \mathrm{~mm}$ ), or LS (AP: $+0.38 \mathrm{~mm}$; ML: $0 \mathrm{~mm}$; DV: $-2.2 \mathrm{~mm}$ ). Optical fibers were secured to the skull using Metabond (Parkell), stainless steel screws (PlasticsOne), and dental cement (DuraLay). Mice recovered for three weeks before MeA stimulation or six weeks before stimulation of MeA axons at the MeA projection sites. Four mice died after viral injection (1.92\% of total). Materials can be found in Table 1 .

Some animals underwent a second surgery six weeks after viral injection to implant optrodes, which were used to record neural activities evoked by optical stimulation (Nabavi et al., 2014; Zhou et al., 2017). The optrode was inserted into the $\mathrm{VmH}, \mathrm{BNST}$, or LS at the same depth as the virus. The craniotomy was sealed with bone wax. Two stainless steel screws were inserted into the skull over the cerebellum and olfactory bulb to be used as ground and reference. Each optrode was outfitted with a microdrive and surrounded by a copper mesh to block external electrical noise. Two mice died after optrode implantation ( $0.96 \%$ of total).

\section{Behavioral tests and data analysis}

All mice were individually housed after foot shock and surgery and for three weeks before baseline aggression testing. On the day of testing, mice were transferred to the behavioral room and allowed to acclimate for $1 \mathrm{~h}$ before commencing behavior experiments. Materials can be found in Table 1.

\section{Foot shock and contextual fear memory test}

Foot shock is a commonly used procedure to induce traumatic stress in rodents (Rau et al., 2005; Bali and Jaggi, 2015; Chang et al., 2015, 2018; Chang and Gean, 2019; Brivio et al., 2020). We adopted a foot shock protocol from Rau et al. (2005). On day 1, mice were placed into a fear conditioning chamber illuminated with white light (Context A) within a sound attenuating cubicle (Med Associates). After a 3-min exploration period, 15 electric shocks (0.4-mA, $1 \mathrm{~s}$ in duration) were administered through an electrified grate at random intervals of 240$480 \mathrm{~s}$ over the course of $90 \mathrm{~min}$. Control mice did not receive foot shock.

For the contextual fear memory test, at $1 \mathrm{~d}$ after foot shock in Context A, mice were placed into the fear conditioning box modified with white plastic walls, no ambient light, and a background odor of 1\% acetic acid (Context B). Mice were left to freely roam within the chamber for $192 \mathrm{~s}$ before a single $1 \mathrm{~s}, 0.4-\mathrm{mA}$ shock was delivered via the electrified grate, and were removed from the chamber at $32 \mathrm{~s}$ after foot shock. On the following day, mice were placed into Context B for $8 \mathrm{~min}$ and $32 \mathrm{~s}$ and were monitored for freezing behavior. Freezing behavior was defined as an absence of all movement, excluding respiration, and was analyzed with Video Freeze software (Med Associates).

\section{Aggression test}

Mice were placed in a high-walled, novel cage and allowed to acclimate for 20 min before introduction of a younger, group-housed conspecific. Both mice were allowed to freely interact for $10 \mathrm{~min}$. Animal behavior was captured with a video camera. Mice were tested for aggression before (baseline test) and after foot shock. Because a further increase in aggression may not be induced in mice with high aggression because of a ceiling effect (O'Donnell et al., 1981; Lee and Gammie, 2009, 2010), only mice exhibiting a total attack time of $<3 \%$ in the baseline test, which was considered as low aggression in previous studies (Hong et al., 2014), were used for further analysis. Eleven mice (5.29\% of total) were excluded based on this criterion. Videos of behavioral tests were reviewed and hand scored by a researcher blind to the experimental conditions. Aggressive behaviors such as chasing, boxing, pinning, and wrestling were identified as reported (Blanchard and Blanchard, 1977; Lin et al., 2011; Koolhaas et al., 2013; Hong et al., 2014; Golden et al., 2016).

\section{Open field test}

The open field test is a commonly used test for locomotion and anxiety-like behavior in mice (Crawley, 1999). Mice were transferred to the behavioral testing room at least $1 \mathrm{~h}$ before testing and then placed into a $49 \times 49 \mathrm{~cm}$ open field arena for $30 \mathrm{~min}$ to freely roam. Distance traveled in the arena was analyzed using TopScan software (CleverSys).

\section{Sociability test}

The sociability test was modified from existing protocols (Silverman et al., 2010). During testing, mice were placed into a $49 \times 49 \mathrm{~cm}$ arena with two inverted wire cups: one empty and the other containing an unfamiliar conspecific. Subject mice were allowed to freely investigate the arena for $30 \mathrm{~min}$. All experiments were conducted under light with a luminescence level of 20 lux at the bottom of the arena (Kaidanovich-Beilin et al., 2011). Social interaction was analyzed using TopScan software (CleverSys) and scored as the ratio of time spent within $5 \mathrm{~cm}$ of the cup containing the animal over the empty cup.

\section{Light/dark box}

The light/dark box test is a commonly used test for anxiety-like behavior in mice (Hascoët and Bourin, 1998; Bourin and Hascoët, 2003). The test room was illuminated with 20 lux light. At time of testing, mice were placed in the light compartment of a light/dark box with dimensions of $46 \times 27 \times 30 \mathrm{~cm}$, where one third of the box was dark and two thirds were transparent. Mice were then allowed to freely explore the test box for $11 \mathrm{~min}$. The box was cleaned with $30 \%$ ethanol and water between runs. The test was recorded using a ceiling mounted camera and then analyzed using automated behavioral tracking software (TopScan/ObjectScan; CleverSystems).

\section{Forced swim test}

The forced swim test is a commonly used test for depression-like behavior (Porsolt et al., 1977; Can et al., 2012). Mice were placed into a large transparent plastic cylinder of height $30 \mathrm{~cm}$ and diameter of $20 \mathrm{~cm}$, filled with fresh water to a height of $20 \mathrm{~cm}$ at $25^{\circ} \mathrm{C}$. The test was conducted for 6 min and was recorded with a Digital camera. An index of despaired behavior was determined by duration of immobility as defined by no movement of limbs except for respiration. Mice were continuously monitored, and no mice drowned during the forced swim test. 
Table 1: Key resources table

\begin{tabular}{|c|c|c|c|c|}
\hline Resource type & Specific reagent or resource & $\begin{array}{l}\text { Source or } \\
\text { reference }\end{array}$ & Identifiers & $\begin{array}{l}\text { Additional } \\
\text { information }\end{array}$ \\
\hline Commercial assay or kit & Metabond & Parkell & Catalog \#S380 & \\
\hline Commercial assay or kit & Dental cement & DuraLay & Catalog \#602-7395 & \\
\hline Commercial assay or kit & $\begin{array}{l}\text { Vectashield HardSet Antifade } \\
\text { Mounting Medium } \\
\text { with DAPI }\end{array}$ & $\begin{array}{l}\text { Vector } \\
\text { Laboratories }\end{array}$ & Catalog \#H-1500 & \\
\hline Organism/strain & C57BL/6J & Charles River & Strain code: 556 & \\
\hline Software; algorithm & SigmaPlot & IBM & https://www.ibm.com & \\
\hline Software; algorithm & TopScan/ObjectScan & CleverSystems & http://cleversysinc.com & \\
\hline Software; algorithm & Video Freeze Software & Med Associates & $\begin{array}{l}\text { https://www.med-associates.com/ } \\
\text { product/video-fear-conditioning/ }\end{array}$ & \\
\hline Software; algorithm & Labview & $\begin{array}{l}\text { National } \\
\text { Instruments }\end{array}$ & $\begin{array}{l}\text { http://www.ni.com/en-us/shop/labview/ } \\
\text { labview-details.html }\end{array}$ & \\
\hline
\end{tabular}

Key resources used in Figs. 1-5 and Extended Fig. 2-1 and Extended Fig. 4-1.

\section{In vivo optogenetic stimulation}

Optogenetic stimulation was performed via an optical fiber (ferrule fiber, ThorLabs) connected through a zirconia split sleeve and patch cord to a 473-nm laser (Coherent) under the control of an Optogenetics TTL Pulse Generator (Doric Lenses).

\section{Electrophysiology}

\section{Optrode fabrication}

A microdrive was assembled from 3D-printed pieces, screws, and nuts, and then attached to a nano-miniature connector (Omnetics) with epoxy glue. The optrode was constructed with sixteen $30-\mu \mathrm{m}$ diameter tungsten wires (California Fine Wire) surrounding a 100- $\mu \mathrm{m}$ diameter optical fiber. One end of the tungsten wire extended $\sim 300 \mu \mathrm{m}$ beyond the tip of the optical fiber, and the other end was wired to pins of a nano-miniature connector. Impedance of each channel in the optrode was measured (usually $\sim 100 \mathrm{k} \Omega$ at $1 \mathrm{kHz}$ ) after construction.

In vivo electrophysiological recording in awake, freely moving mice

The nano-miniature connector on the microdrive was plugged into an amplifier (RHD2132, Intan Technologies). The amplifier was connected to an RHD2000 USB interface board (Intan Technologies) through a motorized commutator (Tucker Davis Technology). Electrical signals were filtered to obtain signals between 1 and $7500 \mathrm{~Hz}$, sampled and digitized at $30 \mathrm{kHz}$ by the amplifier, and recorded by RHD2000 Interface software (Intan Technologies). The 473$\mathrm{nm}$ laser (Coherent) was controlled by a USB-6212 BusPowered DAQ Device (National Instruments) in Labview (National Instruments) virtual instruments. After a two-week recovery period, mice implanted with optrodes were placed into high-walled novel cages inside a grounded faraday cage and allowed to acclimate for 20 min before recording. Video recordings of animal behaviors were obtained via a ceiling mounted acA1300-200uc USB 3.0 camera (Basler) at 30 frames per second simultaneously with electrophysiological recording. Video and electrophysiological recordings were synchronized using Master-8 Pulse Stimulator (A.M.P.I.), which generated and sent an electrical signal for each light pulse and video frame to the RHD2000 recording software (Intan Technologies). Local field potentials (LFPs) were evoked by delivering 1-3 $\mathrm{mW}, 1$-ms light pulses at $0.05-\mathrm{Hz}$ through the implanted optical fiber. Laser power was adjusted to elicit field EPSPs (fEPSPs) with a clear early and late component. In vivo electrophysiological data were analyzed with custom-written MATLAB scripts. Only recordings with all baseline fEPSPs $\geq 90 \%$ of the average baseline fEPSP not significantly different from each other as determined by repeated measures ANOVA test, verified opsin expression, and correct targeting of optrodes were included in further analysis. Two mice $(0.96 \%$ of total recorded mice) were removed based on these criteria.

\section{Production of GFP virus}

HEK-293T cells were cultured on 15-cm plates coated with $0.1 \%$ gelatin in DMEM media supplemented with $10 \%$ fetal bovine serum (Thermo Fisher Scientific). When the cell reached $90 \%$ confluence, the medium was changed at $2 \mathrm{~h}$ before transfection. For transfection of each $15-\mathrm{cm}$ plate, $10 \mu \mathrm{g}$ pRRIsin.CMV.eGFP, $7.5 \mu \mathrm{g}$ psPAX2, $2.5 \mu \mathrm{g}$ pMD2G, and $1 \mu \mathrm{g}$ pAdVantage packaging vector were added to $2 \mathrm{ml}$ water containing $260 \mu \mathrm{l} \mathrm{CaCl}$ $(2 \mathrm{~m})$ and then mixed with $2 \mathrm{ml} 2 \times$ HBSS (50 mm HEPES, $280 \mathrm{~mm} \mathrm{NaCl}$, and $1.5 \mathrm{~mm} \mathrm{Na}_{2} \mathrm{HPO}_{4}, \mathrm{pH}$ 7.05). After incubation at room temperature for $2 \mathrm{~min}$, the mixture was added to the culture plate dropwise. The medium was replaced with $15 \mathrm{ml}$ UltraCULTURE medium (UltraCULTURE, $1 \mathrm{~mm}$ sodium pyruvate, $0.075 \%$ sodium bicarbonate, and $1 \times$ glutamine) at $16 \mathrm{~h}$ after transfection. The medium was removed $48 \mathrm{~h}$ after transfection and kept at $4^{\circ} \mathrm{C}$. A total of 15 $\mathrm{ml}$ fresh UltraCULTURE medium was added to the plate and collected $72 \mathrm{~h}$ after transfection. The media collected at the two times were combined, filtered with 
Table 2: Statistical table

\begin{tabular}{|c|c|c|c|c|c|c|c|}
\hline Data & Method & Factor & $n$ & $\begin{array}{l}F, t, \text { or } \\
U \text { DF }\end{array}$ & $\begin{array}{l}F, t \text {, or } \\
\text { U stat }\end{array}$ & $p$ value & $\begin{array}{l}\text { Post hoc } \\
\text { test }\end{array}$ \\
\hline Figure $1 C$ & Mann-Whitney & Shocks & 6,8 & $U=$ & 2.000 & 0.003 & \\
\hline Figure $1 E$ & Mann-Whitney & Shocks & 6,8 & $U=$ & 0.000 & $<0.001$ & \\
\hline Figure $1 F$ & Mann-Whitney & Shocks & 6,8 & $U=$ & 4.000 & 0.008 & \\
\hline Figure $1 H$ & Mann-Whitney & Shocks & 7,7 & $U=$ & 8.000 & 0.038 & \\
\hline Figure $1 K$ & Mann-Whitney & Shocks & 7,7 & $U=$ & 5.000 & 0.011 & \\
\hline Figure $1 L$ & Mann-Whitney & Shocks & 7,7 & $U=$ & 7.000 & 0.026 & \\
\hline \multirow[t]{2}{*}{ Figure $2 F$} & $\begin{array}{l}\text { Kruskal-Wallis one-way ANOVA } \\
\text { on ranks with Dunn's methods }\end{array}$ & fEPSPs from shocks & 6 & $H_{(2)}=$ & 11.474 & 0.003 & Tukey's \\
\hline & One-way ANOVA & fEPSPs without foot shocks & 3 & $F_{(2,6)}=$ & 2.439 & 0.168 & Tukey's \\
\hline Figure $2 J$ & One-way ANOVA & fEPSPs from shocks & 5 & $F_{(2,12)}=$ & 8.362 & 0.005 & Tukey's \\
\hline Figure $3 B$ & Two-way ANOVA & Virus & $8,8,6$ & $F_{(1,19)}=$ & 0.383 & 0.543 & Tukey's \\
\hline \multirow[t]{2}{*}{ Figure $3 C$} & Two-way ANOVA & LFPS from shocks & $7,7,5$ & $F_{(1,16)}=$ & 6.024 & 0.026 & Tukey's \\
\hline & & Virus & $7,7,5$ & $F_{(1,16)}=$ & 7.437 & 0.015 & Tukey's \\
\hline \multirow[t]{2}{*}{ Figure $3 D$} & Two-way ANOVA & LFPS from shocks & $7,7,5$ & $F_{(1,16)}=$ & 4.595 & 0.048 & Tukey's \\
\hline & & Virus & $7,7,5$ & $F_{(1,16)}=$ & 10.286 & 0.005 & Tukey's \\
\hline \multirow[t]{2}{*}{ Figure $3 E$} & Two-way ANOVA & LFPS from shocks & $7,7,5$ & $F_{(1,16)}=$ & 8.776 & 0.009 & Tukey's \\
\hline & & Virus & $7,7,5$ & $F_{(1,16)}=$ & 6.137 & 0.025 & Tukey's \\
\hline \multirow[t]{2}{*}{ Figure $3 F$} & Two-way ANOVA & LFPS from shocks & $7,7,5$ & $F_{(1,16)}=$ & 5.844 & 0.028 & Tukey's \\
\hline & & Virus & $7,7,5$ & $F_{(1,16)}=$ & 4.969 & 0.04 & Tukey's \\
\hline \multirow[t]{2}{*}{ Figure $3 H$} & Two-way ANOVA & LFPS from shocks & $7,7,5$ & $F_{(1,21)}=$ & 2.704 & 0.115 & Tukey's \\
\hline & & Virus & $7,7,5$ & $F_{(1,21)}=$ & 2.085 & 0.163 & Tukey's \\
\hline \multirow[t]{2}{*}{ Figure 3l } & Two-way ANOVA & LFPS from shocks & $7,7,5$ & $F_{(1,21)}=$ & 0.223 & 0.641 & Tukey's \\
\hline & & Virus & $7,7,5$ & $F_{(1,21)}=$ & 1.603 & 0.219 & Tukey's \\
\hline \multirow[t]{2}{*}{ Figure $5 B$} & Two-way ANOVA & Shocks & $6,10,7$ & $F_{(1,20)}=$ & 0.018 & 0.895 & Tukey's \\
\hline & & LFPS vs no stim & $6,10,7$ & $F_{(1,20)}=$ & 5.588 & 0.028 & Tukey's \\
\hline \multirow[t]{2}{*}{ Figure $5 C$} & Two-way ANOVA & Shocks & $6,10,7$ & $F_{(1,20)}=$ & 1.167 & 0.293 & Tukey's \\
\hline & & LFPS vs no stim & $6,10,7$ & $F_{(1,20)}=$ & 0.600 & 0.448 & Tukey's \\
\hline \multirow[t]{2}{*}{ Figure $5 D$} & Two-way ANOVA & Shocks & $6,10,7$ & $F_{(1,20)}=$ & 0.292 & 0.595 & Tukey's \\
\hline & & LFPS vs no stim & $6,10,7$ & $F_{(1,20)}=$ & 12.715 & 0.002 & Tukey's \\
\hline \multirow[t]{2}{*}{ Figure $5 E$} & Two-way ANOVA & Shocks & $6,10,7$ & $F_{(1,20)}=$ & 1.944 & 0.179 & Tukey's \\
\hline & & LFPS vs no stim & $6,10,7$ & $F_{(1,20)}=$ & 5.262 & 0.033 & Tukey's \\
\hline Figure $5 F$ & Two-way ANOVA & Shocks & $6,8,6$ & $F_{(1,17)}=$ & 0.155 & 0.698 & Tukey's \\
\hline & & LFPS vs no stim & $6,8,6$ & $F_{(1,17)}=$ & 7.25 & 0.015 & Tukey's \\
\hline Figure 5G & Two-way ANOVA & Shocks & $6,8,6$ & $F_{(1,17)}=$ & 0.281 & 0.603 & Tukey's \\
\hline & & LFPS vs no stim & $6,8,6$ & $F_{(1,17)}=$ & 5.694 & 0.029 & Tukey's \\
\hline Figure $5 H$ & Two-way ANOVA & Shocks & $6,8,6$ & $F_{(1,17)}=$ & 0.007 & 0.937 & Tukey's \\
\hline & & LFPS vs no stim & $6,8,6$ & $F_{(1,17)}=$ & 6.973 & 0.017 & Tukey's \\
\hline Figure 5l & Two-way ANOVA & Shocks & $6,8,6$ & $F_{(1,17)}=$ & 0.589 & 0.453 & Tukey's \\
\hline & & LFPS vs no stim & $6,8,6$ & $F_{(1,17)}=$ & 8.380 & 0.010 & Tukey's \\
\hline $\begin{array}{l}\text { Extended Data } \\
\text { Figure } 4-1 B\end{array}$ & One-way ANOVA & fEPSPs from shocks & 6 & $F_{(2,15)}=$ & 6.752 & 0.008 & Tukey's \\
\hline $\begin{array}{l}\text { Extended Data } \\
\text { Figure } 4-1 D\end{array}$ & One-way ANOVA & fEPSPs from shocks & 5 & $F_{(2,12)}=$ & 7.690 & 0.007 & Tukey's \\
\hline
\end{tabular}


$0.45-\mu \mathrm{m}$ filter bottles, and centrifuged at $25,000 \mathrm{rpm}$ for 90 min at $4^{\circ} \mathrm{C}$ (Beckman, SW28 rotor). The supernatant was removed, and the pellet containing the virus was dissolved by incubation with $100 \mu \mathrm{l} 1 \times$ HBSS overnight at $4^{\circ} \mathrm{C}$. For further purification of virus, the viral suspension was placed on the top of $1.5 \mathrm{ml} 20 \%$ sucrose (in $1 \times$ HBSS) and centrifuged at $21,000 \mathrm{rpm}$ for $2 \mathrm{~h}$ at $4^{\circ} \mathrm{C}$ (Beckman, SW55 rotor). The pellet was incubated with $100 \mu \mathrm{l} 1 \times \mathrm{HBSS}$ overnight at $4^{\circ} \mathrm{C}$, aliquoted and stored at $-80^{\circ} \mathrm{C}$. The titer of purified virus was determined by transducing HEK-293T cells with a series of dilutions. All viruses used for in vivo injection had a titer of $10^{9}$ $10^{10} \mathrm{IU} / \mathrm{ml}$. We elected to use the GFP virus as it was routinely made and confirmed for transduction efficiency in our lab.

\section{Image acquisition and image analysis}

Brain slices were imaged with a multi-slide fluorescent microscope (Zeiss Axio Scan) with a $10 \times($ NA 0.45) objective to locate viral expression and optrode placement at regions of interest. The location of optrodes were determined from the electrode tract left in the brain tissue. In some images, boundaries can be seen between two adjacent areas because of uneven illumination between tiles. Z-stack confocal images were collapsed and analyzed with ImageJ by researchers blind to the experimental conditions.

\section{Statistical analysis}

All data were presented as individual data points or expressed as mean \pm SEM. SigmaPlot software was used for statistical analysis. To compare two groups, two-tailed Student's $t$ test was used if the data were normally distributed with equal variance, and Mann-Whitney $U$ test was used if the data did not satisfy both the normality and equivariance tests. To compare three or more groups, one-way ANOVA or Kruskal-Wallis one-way ANOVA on ranks with Dunn's methods and Tukey's test for post hoc multiple comparisons were used. To analyze three or more groups injected with two different viruses, two-way ANOVA and Tukey's test for post hoc multiple comparisons were used. To analyze in vivo electrophysiological data, repeated measures ANOVA was used for group differences across days, and two-tailed paired Student's $t$ test was used to compare day 1 and day 7 recordings to baseline; $p<0.05$ was considered significant.

\section{Results}

\section{Traumatic stress induces prolonged increases in aggression}

Previous studies show that attack behavior increases at 30 min after traumatic stress induced by electric foot shock (Chang et al., 2015, 2018; Chang and Gean, 2019). To test whether the aggression increase following traumatic stress is long lasting, we administered a traumatic stress protocol by delivering 15 -foot shocks at $0.4 \mathrm{~mA}$ randomly spaced over a 90-min period (Rau et al., 2005). Foot shocks were temporally randomized as unpredictable threat is more effective in producing sustained fear (Davis et al.,
2010). Since only socially isolated mice show aggression increase after foot shock (Veenema, 2009; Toth et al., 2011; Chang et al., 2015, 2018; Zelikowsky et al., 2018; Chang and Gean, 2019), and heightened aggression is more prevalent in men than women suffering from PTSD and after social isolation in males than females in mice, Drosophila, and non-human primates (Gluck and Sackett, 1974; Rodgers and Cole, 1993; Tolin and Foa, 2006; Bubak et al., 2019), only male mice were used in this study.

Male mice (10-week-old) were individually housed for three weeks before shock. Control mice were left in the fear conditioning box for the same amount of time but with no foot shocks. One day after foot shock, mice were divided into two groups and tested for stress-enhanced fear learning (SEFL) and aggression (Fig. 1A). To test for SEFL, mice were placed into a novel environment (Context B) and received one-foot shock (1 $\mathrm{mA})$ followed by assessment of freezing behavior in Context $B 1 \mathrm{~d}$ after (Fig. 1A). Freezing in Context $\mathrm{B}$ was significantly enhanced compared with control mice (Fig. 1B), indicating that fear learning is enhanced by foot shock as previously reported (Rau et al., 2005). To evaluate the long-term effect of traumatic stress on aggression, aggression tests were performed $7 \mathrm{~d}$ after foot shock (Fig. 1A). Four parameters of attack behavior commonly used to examine aggression were measured: overall attack time, number of attacks, duration of each attack, and latency to the first attack (Hong et al., 2014; Golden et al., 2016; Todd et al., 2018). Consistent with previous reports (Haller et al., 2006; Nelson, 2006), foot shock significantly increased attack time, attack number, and attack duration, while decreasing latency to the first attack (Fig. 1C-F).

In addition to aggression, we examined the effect of foot shock on sociability, anxiety-like behavior, and depression-like behavior. Anxiety-like behavior was evaluated using the open field and light/dark box tests (Hascoët and Bourin, 1998), sociability was examined using the social interaction test (Silverman et al., 2010), and depression-like behavior was examined using the forced swim test (Porsolt et al., 1977). These tests were ordered as illustrated in Figure $1 G$ and spaced with a 2-d interval to minimize the effect of stress related to behavioral testing. Foot shocked mice spent less time in the center of an open field arena (Fig. $1 H$ ), in the light compartment of a light/dark box (Fig. $1 K$ ), and were immobile for a longer duration during the forced swim test (Fig. 1L). No change was observed for distance traveled during the open field test (Fig. 1/) and in the social interaction score (SI, the ratio of time spent exploring a mouse to that exploring an object) during the SI test (Fig. 1J).

These results indicate that traumatic stress has longterm effects on aggression, anxiety-like behavior, and depression-like behavior and that the behavioral alterations of shocked mice are not caused by changes in locomotion or sociability.

\section{Traumatic stress induces long-term synaptic potentiation in MeA-VmH and MeA-BNST synapses}

$\mathrm{MeA}$ and its downstream synaptic partners, the $\mathrm{VmH}$, BNST, and LS, are key regions in the aggression circuit, 
A
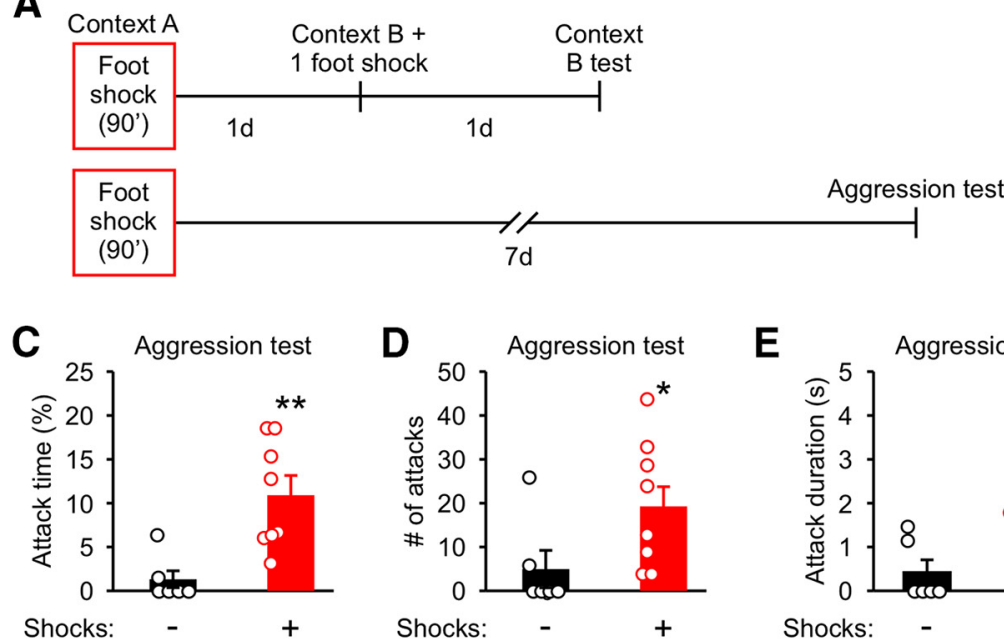

G
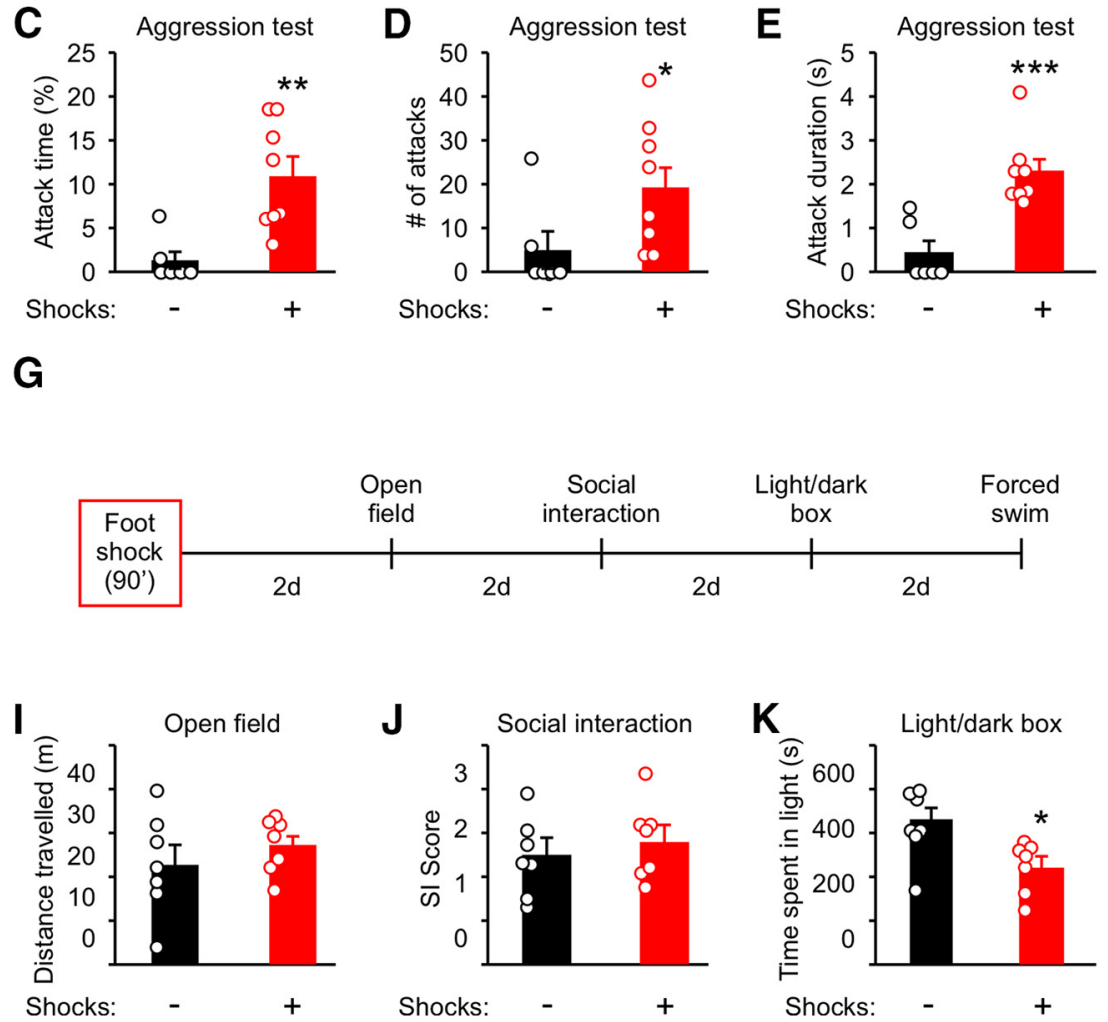
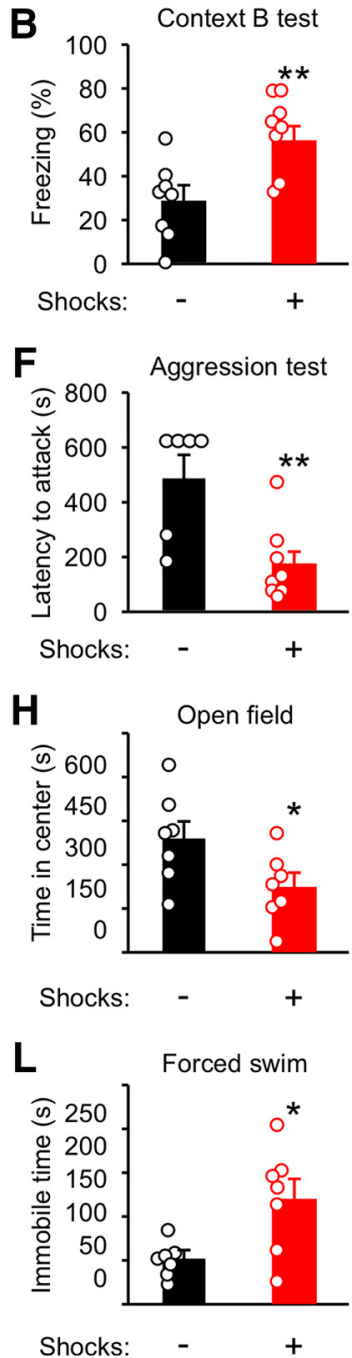

Figure 1. Traumatic stress enhances aggression, fear learning, and anxiety-like and depression-like behaviors while preserving non-aggressive social interactions. $\boldsymbol{A}$, Experimental schedule for $\boldsymbol{B}-\boldsymbol{F}$. Ten-week-old mice were individually housed for three weeks before foot shock. Control animals were placed into Context $A$ for the same amount of time but with no foot shocks applied. Different cohorts were used for $\boldsymbol{B}, \boldsymbol{C}-\boldsymbol{F}, \boldsymbol{H}-\boldsymbol{L}$. $\boldsymbol{B}$. Analysis of freezing behavior in Context B. $\boldsymbol{C}-\boldsymbol{F}$, Analysis of attack behavior $7 \mathrm{~d}$ after foot shock. G, Experimental schedule for $\boldsymbol{H}-\boldsymbol{L}$. $\boldsymbol{H}$, Time in the center of the arena in the open field test. I, Distance traveled during the open field test. $\boldsymbol{J}$, Ratio of time spent interacting with the cup containing a mouse to the time interacting with the empty cup (SI score) during the social interaction test. $\boldsymbol{K}$, Time spent in the light compartment during the light/dark box test. $\boldsymbol{L}$, Time spent immobile during the forced swim test. Data are presented as mean \pm SEM; $* p<0.05, * * p<0.01, * * * p<0.001$. Detailed statistics found in Table 2.

and they have been implicated in traumatic stress-induced behavioral changes (Rodgers, 1977; Puciłowski et al., 1985; Shaikh et al., 1986; Nikulina et al., 2004; Nelson and Trainor, 2007; Silva et al., 2013; Butler et al., 2015; Masugi-Tokita et al., 2016; Wong et al., 2016; Hashikawa et al., 2017). The $\mathrm{VmH}$ in particular has been shown to mediate the acute effect of foot shock on attack behavior (Chang and Gean, 2019). Previously, it has been shown that 1-h restraint stress switches cannabinoid type-1 receptor-dependent synaptic plasticity in the BNST from long-term depression (LTD) to longterm potentiation (LTP) and that social instability stress causes changes in synaptic proteins at the $\mathrm{MeA}$ and LS (Glangetas et al., 2013; Hodges et al., 2019). Hence, it is possible that foot shock may alter synaptic transmission between the MeA and its downstream target regions. To test this possibility, we analyzed the strength of synapses between the MeA and the $\mathrm{VmH}$, BNST, and LS in awake, behaving mice. To this end, six-week-old mice were injected with AAV channelrhodopsin-2 (ChR2) virus into the MeA and then implanted with optrodes into the $\mathrm{VmH}$, BNST, or LS six weeks later (Fig. 2A,C,G,K). ChR2 expression was readily observed in MeA cell bodies (Fig. 2B) and MeA axons at all three projection sites by two weeks after virus injection when in vivo electrophysiological recordings were performed (Fig. $2 D, H, L)$. Optically evoked fEPSPs were obtained at $30 \mathrm{~min}$ before, $1 \mathrm{~d}$, and $7 \mathrm{~d}$ after foot shock, or without foot shock to rule out any potential handling effects. Optically evoked fEPSPs were analyzed by obtaining the slope derived by 
A

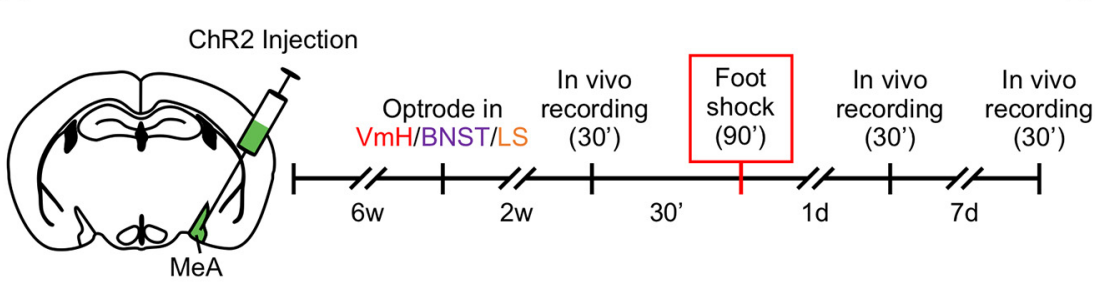

B

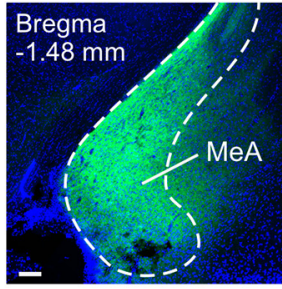

C

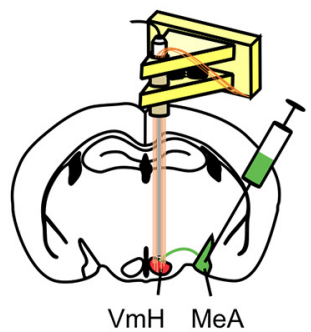

D

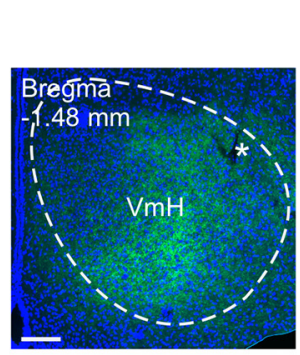

G

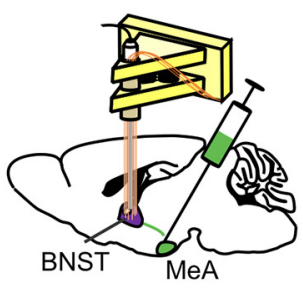

H

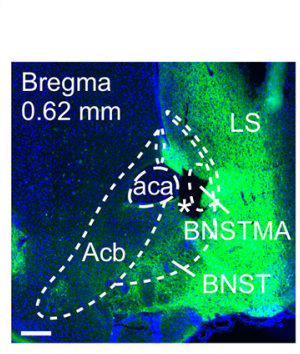

L

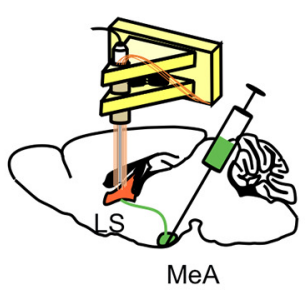

E

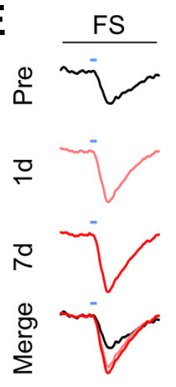

I

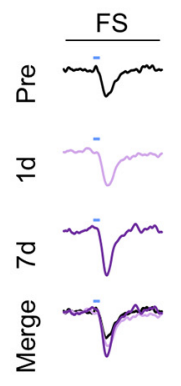

M

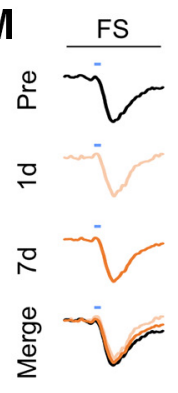

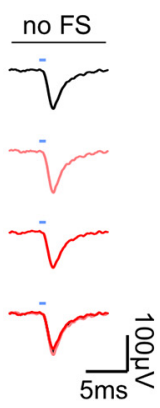

F

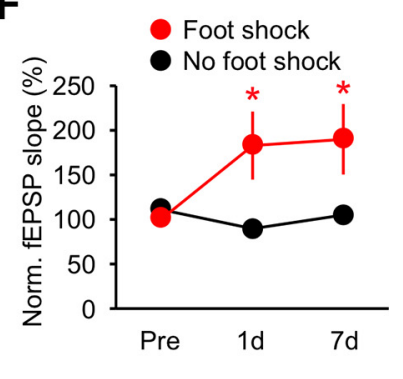

J<smiles>CCCCCC</smiles>

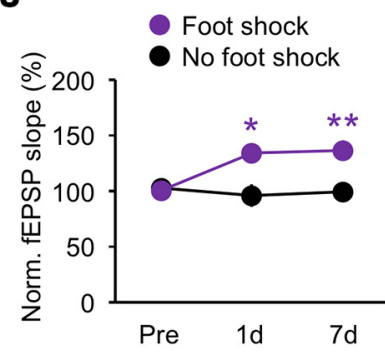

$\mathrm{N}$

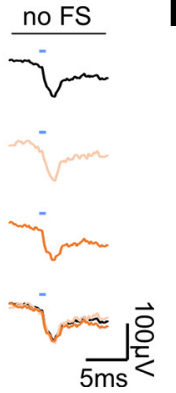

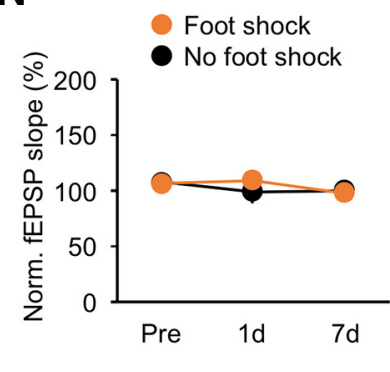

Figure 2. Traumatic stress induces LTP of MeA-VmH and MeA-BNST synapses. A, Experimental schedule for in vivo electrophysiology. Individually housed mice were injected with $\mathrm{ChR} 2$ virus into the MeA and six weeks later were implanted with optrodes into the $\mathrm{VmH}$, BNST, or LS. LFPs evoked by stimulating MeA axons at the $\mathrm{VmH}$, BNST, or LS were recorded for 30 min. $\boldsymbol{B}$, Representative image of ChR2 expression at the MeA. Scale bar: $200 \mu \mathrm{m} . \boldsymbol{C}, \boldsymbol{D}, \boldsymbol{G}, \boldsymbol{H}, \boldsymbol{K}, \boldsymbol{L}$, Illustrations for the sites of viral injection and optrode placement $(\boldsymbol{C}, \boldsymbol{G}, \boldsymbol{K})$ and representative images of ChR2 expression in MeA axons at the VmH $(\boldsymbol{D})$, BNST $(\boldsymbol{H})$, or LS $(\boldsymbol{L})$. Scale bars: $200 \mu \mathrm{m}(\boldsymbol{D}), 200 \mu \mathrm{m}(\boldsymbol{H})$, and $100 \mu \mathrm{m}(\boldsymbol{L})$. $\boldsymbol{E}, \boldsymbol{I}, \boldsymbol{M}$, Representative traces of optically evoked responses at the VmH (E), BNST (I), or LS $(\boldsymbol{M})$ recorded before, $1 \mathrm{~d}$, and $7 \mathrm{~d}$ after foot shock or without foot shock. $\boldsymbol{F}, \boldsymbol{J}, \boldsymbol{N}$, Average slopes of 90 light-evoked fEPSPs recorded at the $\mathrm{VmH}(\boldsymbol{F})$, BNST $(\boldsymbol{J})$, or LS $(\boldsymbol{N})$ before (pre), $1 \mathrm{~d}$, and $7 \mathrm{~d}$ after foot shock or without foot shock (normalized to preshock). Data are presented as mean $\pm \mathrm{SEM} ; * p<0.05, * * p<0.01$. See Extended Data Figure 2-1 for more details. Detailed statistics found in Table 2.

fitting the rising phase of the late component of the fEPSP (excluding the bottom and top 10\%) with linear regression as described previously (Extended Data Fig. 2-1; Xiong et al., 2015; Zhou et al., 2017). Both the VmH and BNST showed sustained increases in fEPSPs after foot shock (Fig. $2 E, F, I, J)$. Conversely, no changes were observed at the LS or in the no foot shock group (Fig. $2 E, F, I, J, M, N$ ). These results indicate that foot shock induces long-term synaptic potentiation in the MeA-VmH and MeA-BNST, but not in the MeA-LS, synapses.

To assess whether synaptic potentiation in the MeA circuit mediates the increases in attack behavior from foot shock, we used an optogenetic synaptic depression protocol (900 pulses of 1-Hz stimulation, LFPS) which is proven effective in vivo (Nabavi et al., 2014; Zhou et al., 2017) to reduce synaptic strength. Ten-week-old socially isolated mice were 
A

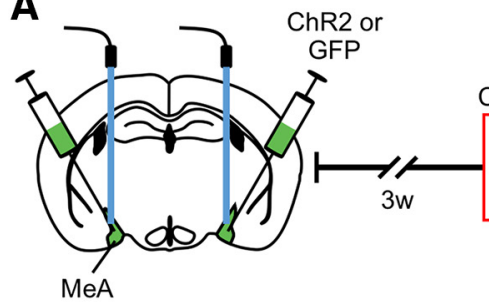

C

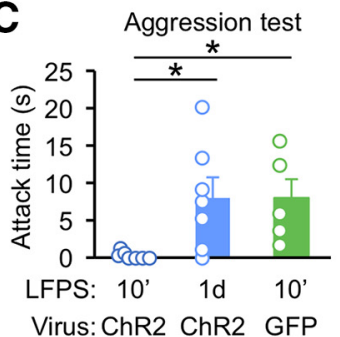

D
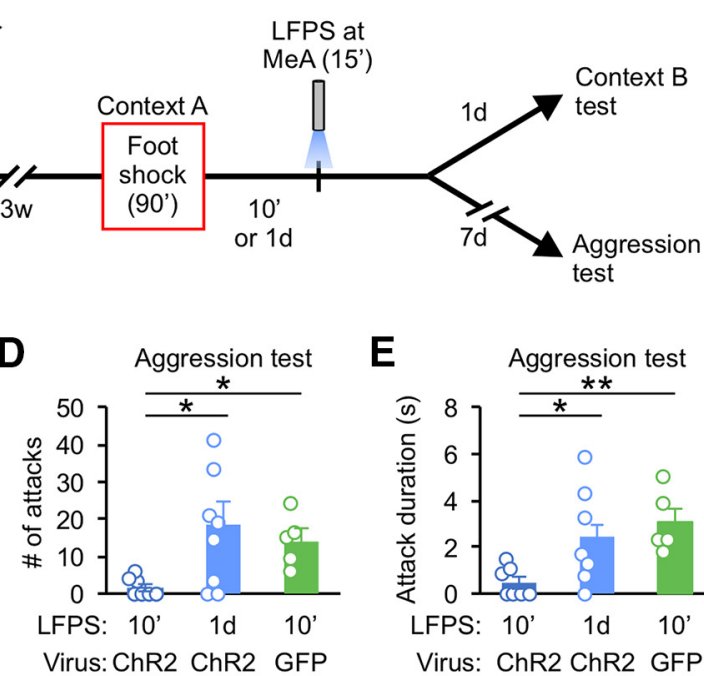

B

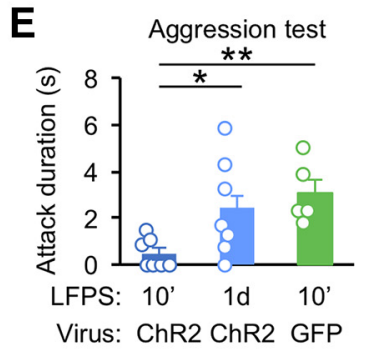

$\mathbf{F}$
B Context B test
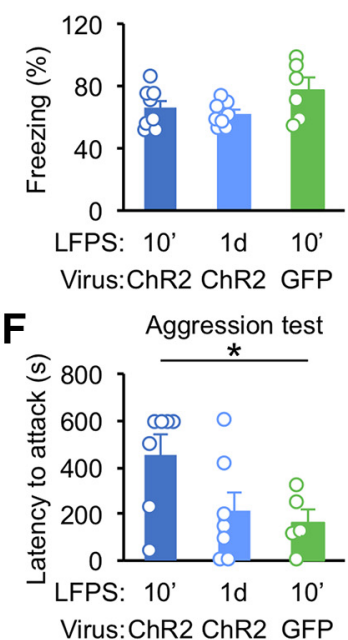

H

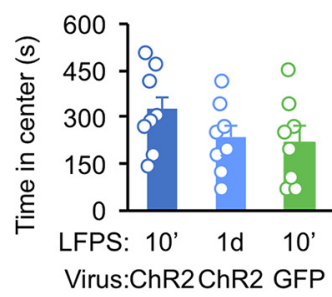

$\mathbf{L}$

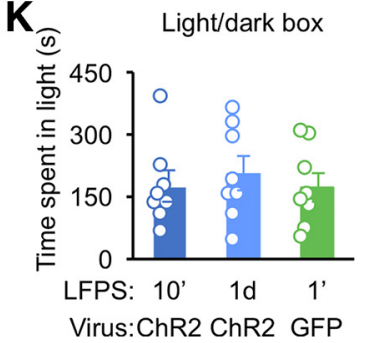

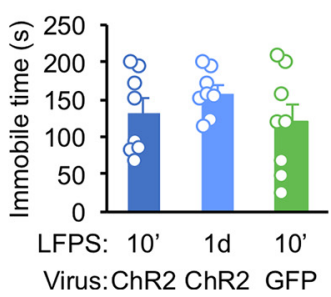

Figure 3. LFPS immediately after traumatic stress suppresses attack behavior. $\boldsymbol{A}$, Experimental protocol for $\boldsymbol{B}-\boldsymbol{F}$. Mice were injected with ChR2 or GFP into the MeA and implanted with optical fibers above. After foot shock, LFPS was delivered immediately or $1 \mathrm{~d}$ after. Different mice were tested in $\boldsymbol{B}, \boldsymbol{C}-\boldsymbol{F}, \boldsymbol{H}-\boldsymbol{L}$. $\boldsymbol{B}$, Analysis of freezing behavior in Context B. $\boldsymbol{C}-\boldsymbol{F}$, Analysis of attack behavior $7 \mathrm{~d}$ after foot shock. $\boldsymbol{G}$, Experimental protocol for $\boldsymbol{H}-\boldsymbol{L}$. $\boldsymbol{H}$, Time in the center of the arena in the open field test. $\boldsymbol{I}$, Distance traveled during the open field test. $\boldsymbol{J}$, Ratio of time spent interacting with the cup containing a mouse to the time interacting with the empty cup (SI score) during the social interaction test. $\boldsymbol{K}$, Time spent in the light compartment during the light/dark box test. $\boldsymbol{L}$, Time spent immobile during the forced swim test. Data are presented as mean $\pm \mathrm{SEM} * p<0.05, * * p<0.01$. Detailed statistics found in Table 2.

injected with ChR2 virus or GFP virus into the MeA and optical fibers were implanted above. Three weeks later, mice were delivered 15 foot shocks and then returned to their home cages. In separate groups, mice were delivered LFPS immediately or $1 \mathrm{~d}$ after foot shock (Fig. $3 A$ ). Mice injected with ChR2 virus and stimulated with LFPS immediately, but not $1 \mathrm{~d}$ after, foot shock were less aggressive than mice injected with GFP virus and stimulated with LFPS (Fig. 3C-F). LFPS applied immediately or $1 \mathrm{~d}$ after foot shock had no effect on contextual fear memory, anxiety-like behavior, depression-like behavior, sociability, or locomotion (Fig. 3B,H-L).

These results indicate that foot shock induces potentiation of synapses between MeA and its synaptic partners and that there is a critical period to prevent foot shock-induced aggression increase via synaptic depression.

\section{Potentiation of the MeA-VmH and MeA-BNST synapses is required for foot shock-induced aggression increase}

Having found that foot shock induces synaptic potentiation in the MeA-VmH and MeA-BNST synapses, we tested whether the effect of LFPS at the MeA is mediated by the MeA-VmH and MeA-BNST synapses. We injected ChR2 virus into the MeA of seven-week-old mice and implanted optrodes into the $\mathrm{VmH}$ or BNST six weeks later. Mice were then delivered foot shocks followed immediately after by LFPS (Fig. 4A). Optically evoked fEPSPs at $\mathrm{MeA}-\mathrm{VmH}$ and MeA-BNST synapses were recorded in 
A

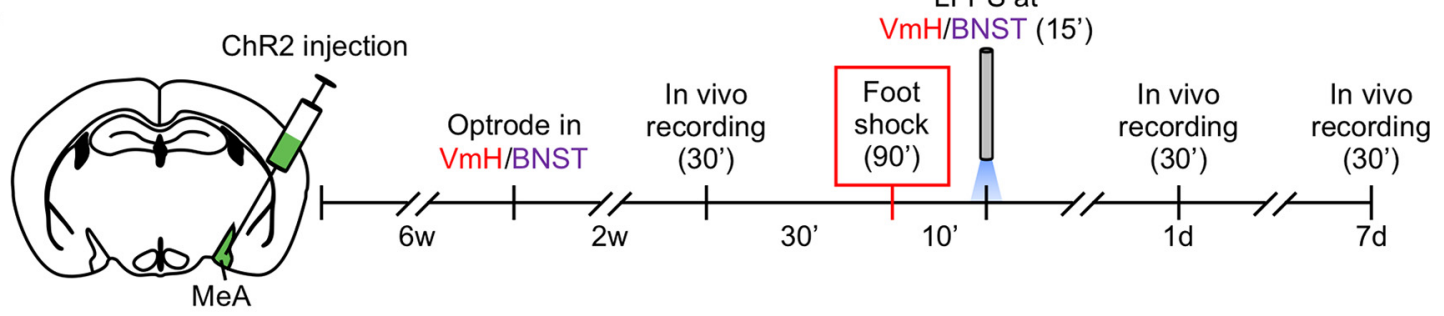

B

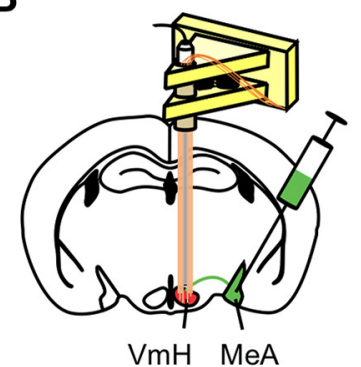

E

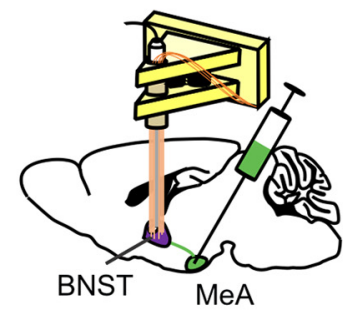

C

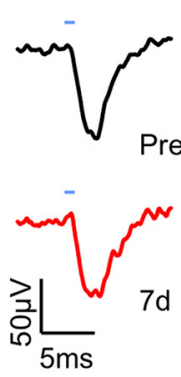

F

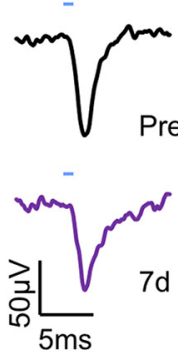

D
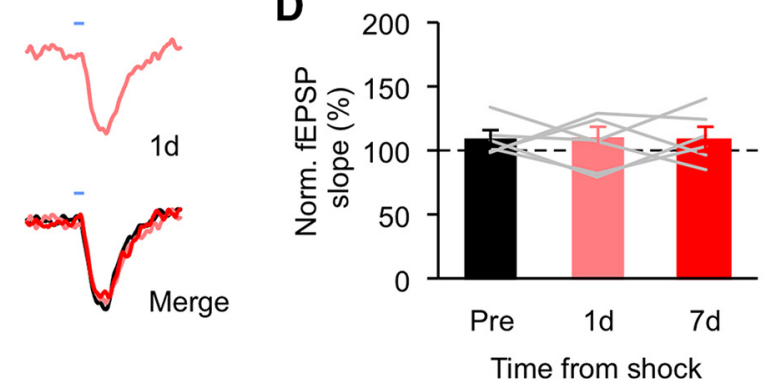

G

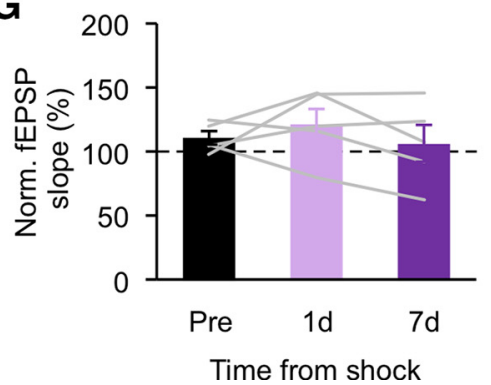

Figure 4. LFPS at the MeA-VmH and MeA-BNST synapses abolishes foot shock-induced synaptic potentiation. $\boldsymbol{A}$, Experimental schedule for in vivo electrophysiology. LFPS was delivered to the VmH and BNST immediately after foot shock. $\boldsymbol{B}$, $\boldsymbol{E}$, Illustrations for the sites of viral injection at the MeA and optrode placement at the $\mathrm{VmH}(\boldsymbol{B})$ or BNST $(\boldsymbol{E})$. $\boldsymbol{C}, \boldsymbol{F}$, Representative traces of optically evoked responses at the $\mathrm{VmH}(\boldsymbol{C})$ or BNST $(\boldsymbol{F})$ recorded before, $1 \mathrm{~d}$, and $7 \mathrm{~d}$ after foot shock. $\boldsymbol{D}$, $\boldsymbol{G}$, Normalized slopes of lightevoked fEPSPs recorded at the $\mathrm{VmH}(\boldsymbol{D})$ or BNST $(\boldsymbol{G})$ before and after foot shock. Data are presented as mean \pm SEM. See Extended Data Figure 4-1 for more details. Detailed statistics found in Table 2.

vivo before and after foot shock. fEPSPs recorded before, $1 \mathrm{~d}$, and $7 \mathrm{~d}$ after foot shock were comparable (Fig. 4BG). Importantly, we confirmed that LFPS depotentiated the MeA-VmH and MeA-BNST synapses that were potentiated by foot shock by recording fEPSPs immediately after foot shock and then immediately after LFPS (Extended Data Fig. 4-1).

To assess whether the MeA-VmH and MeA-BNST synapses are responsible for the effect of LFPS on foot shock-induced aggression increase, we applied LFPS to the MeA projections to the $\mathrm{VmH}$ and BNST immediately after foot shock and evaluated aggression $7 \mathrm{~d}$ later (Fig. $5 A$ ). Mice that received LFPS at the MeA-VmH and MeABNST projections immediately after foot shock displayed less overall attack time as well as shorter duration of each attack compared with mice that received foot shock but without LFPS (Fig. 5B-l). LFPS at MeA-BNST synapses also decreased the number of attacks and latency to the first attack (Fig. 5C,E).

Taken together, these findings indicate that potentiation of the MeA- $\mathrm{VmH}$ and MeA-BNST synapses underlie the prolonged aggression increase induced by traumatic stress through foot shock.

\section{Discussion}

Traumatic stress can increase aggression (Nelson, 2006). Previous studies have shown that traumatic stress induced by foot shock can prime animals to attack and increase anxiety and depression-like behaviors (Chang et al., 2015, 2018; Chang and Gean, 2019). These effects were measured at 30 min after foot shock. The long-term effect of foot shock on attack behavior has not been explored. In this study, we find that foot shock causes an increase in attack that lasts for at least $7 \mathrm{~d}$, while preserving locomotion and sociability. As the MeA is a key area mediating aggressive behavior, we further investigated the role of the MeA in this enhancement. In vivo electrophysiological recordings revealed that the $\mathrm{MeA}-\mathrm{VmH}$ and $\mathrm{MeA}-$ BNST synapses were potentiated for up to $7 \mathrm{~d}$ after foot shock. No effects were found at the LS, another region involved in stress and aggression, and a downstream synaptic partner of the MeA. LFPS suppressed shock- 
A
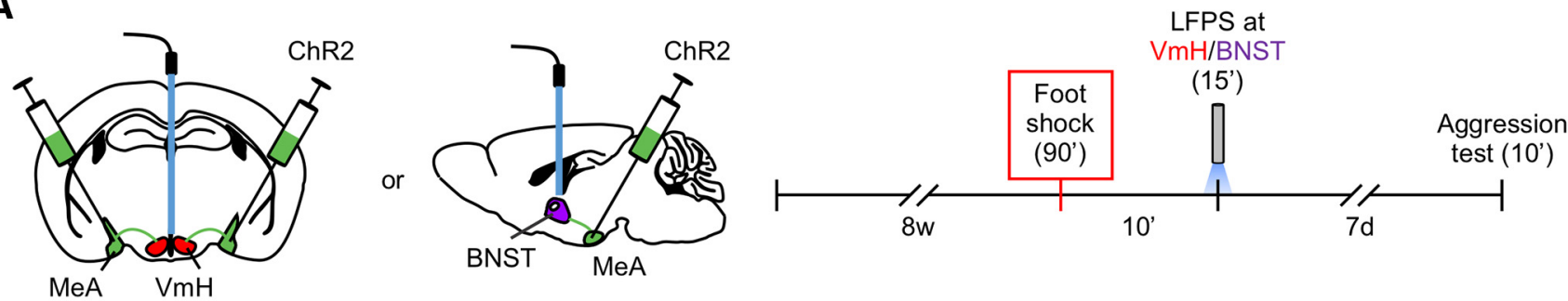

B

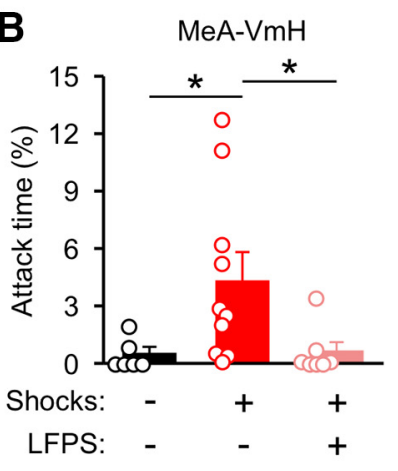

$\mathbf{F}$

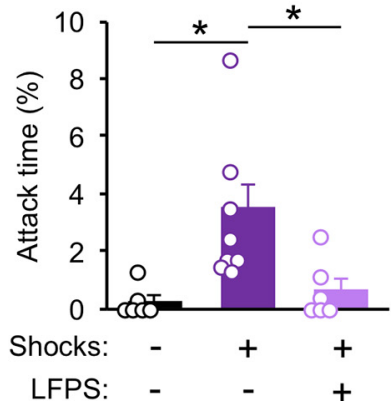

C

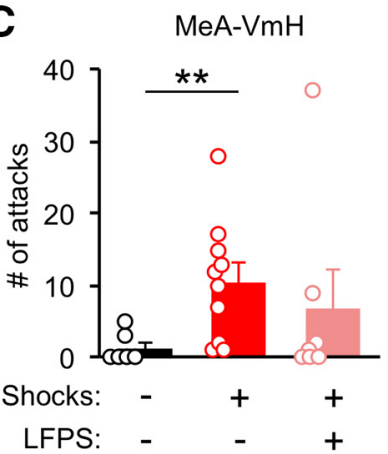

G

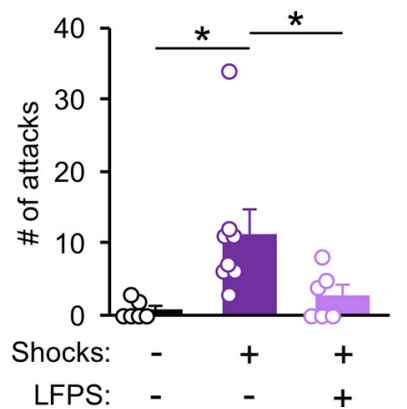

D

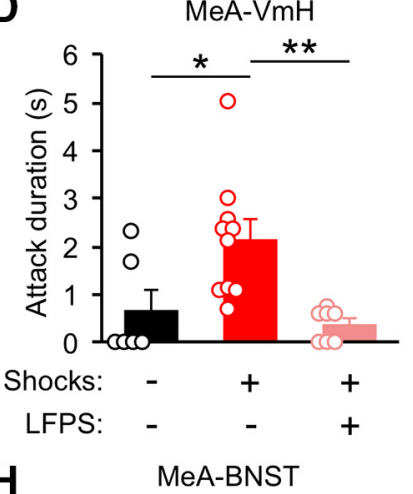

H

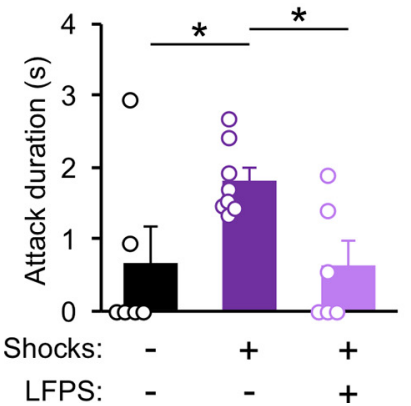

E

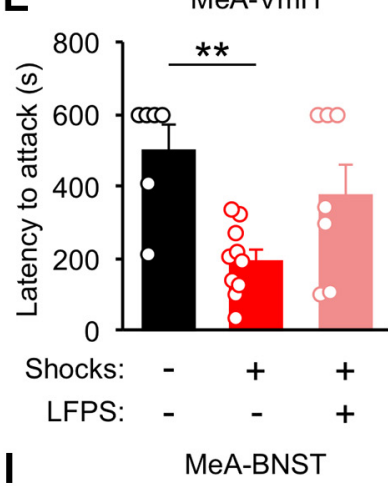

1

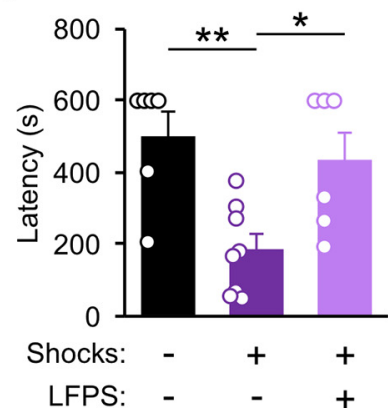

Figure 5. LFPS of the MeA-VmH and MeA-BNST synapses suppresses foot shock-induced aggression increase. $\boldsymbol{A}$, Experimental protocol. LFPS was delivered to the $\mathrm{VmH}$ or BNST immediately after foot shock. B-I, Analysis of attack behavior $7 \mathrm{~d}$ after foot shock. Data are presented as mean \pm SEM; $* p<0.05, * * p<0.01$. Detailed statistics found in Table 2.

induced potentiation of MeA-VmH and MeA-BNST synapses. LFPS also suppressed foot shock-induced aggression enhancement when applied to the MeA or the $\mathrm{MeA}-\mathrm{VmH}$ and MeA-BNST synapses, indicating that potentiation of the MeA-VmH and MeA-BNST pathways is necessary for changes in attack behavior.

A natural question is how social exposure at $7 \mathrm{~d}$ after traumatic stress drives an aggressive response. One possibility is that potentiation of the MeA-VmH and MeA-BNST pathways results in a general increase in arousal that sets the mouse in a constant state of social alertness independent of social cues. High social arousal is expected to be reflected in social interactions. We see no changes in sociability or non-aggressive social behavior during the aggression test. Additionally, while LFPS of the MeA-VmH and MeA-BNST synapses suppressed foot shock-induced aggression increase, it did not alter non-aggressive social behaviors. These findings suggest that foot shock specifically affects aggressive behavior rather than general social interaction through the MeA-VmH and MeA-BNST pathways.

Previous studies have demonstrated a link between the $\mathrm{VmH}$ and BNST to attack behavior (Nelson and Trainor,
2007; Hashikawa et al., 2017). Both regions are also associated with stress responses. The $\mathrm{VmH}$ and BNST are activated by social and physical stress, with the $\mathrm{VmH}$ driving defensive responses to a predator and the $\mathrm{VmH}$ and BNST regulating anxiolytic responses to foot shock (Dennis, 1976; Jennings et al., 2013; Kim et al., 2013; Silva et al., 2013; Anthony et al., 2014; Butler et al., 2015; Zelikowsky et al., 2018). Recently, the $\mathrm{VmH}$ was shown to underlie attack behavior measured at $30 \mathrm{~min}$ after foot shock (Chang and Gean, 2019). The MeA is an afferent pathway for the $\mathrm{VmH}$ and the BNST, and these circuits have been implicated in aggression. MeA neurons expressing dopamine D1 receptors and projecting onto the $\mathrm{VmH}$ and BNST regulate fighting during the resident intruder assay (Miller et al., 2019). GABAergic neurons expressing the neuropeptide $Y$ type 1 receptor (Npy1R) in the $\mathrm{MeA}$ receive input from $\mathrm{VmH}$ neurons and subsequently project onto the BNST to modulate territorial aggression during starvation (Padilla et al., 2016). It remains unclear, however, what role these pathways play in the aggression increase resulting from traumatic stress. We show here that the MeA controls foot shock-induced 
prolonged aggression increase through potentiation of the MeA-VmH and MeA-BNST synapses and that depotentiation of these synapses can suppress these increases in attack behavior. The MeA-VmH and MeA-BNST pathways may have non-redundant or overlapping functions in traumatic stress-induced aggression. A more detailed examination of these pathways is warranted to address this question.

It has been shown that foot shock induces attack behavior only after social isolation (Veenema, 2009; Toth et al., 2011; Chang et al., 2015, 2018; Zelikowsky et al., 2018; Chang and Gean, 2019) and that heightened aggression after social isolation is more prevalent in male than female animals (Gluck and Sackett, 1974; Rodgers and Cole, 1993; Bubak et al., 2019). In addition, high-aggression mice may not be able to further increase aggression because of a ceiling effect (O'Donnell et al., 1981; Lee and Gammie, 2009, 2010). We, therefore, elected to use socially isolated male mice that demonstrated low-aggression levels before foot shock to examine the effect of traumatic stress on aggression. It cannot be ruled out though that limiting our cohort to socially isolated, low-aggression mice may constrain the generalizability of our findings. It is possible that the increase in attack behavior after traumatic stress is attributable, at least in part, to sensitization of the MeA by social isolation. Thus, potentiation of the MeA circuit may be a mechanism for traumatic stress-induced aggression only under certain conditions. Future studies assessing the effect of social isolation on synaptic physiology of the MeA pathways and experiments using group-housed mice would address this question. However, optrode implantation poses technical challenges to postsurgery group housing.

Finally, the finding that LFPS can suppress foot shock-induced attack increase when applied immediately but not $1 \mathrm{~d}$ after shock indicates that depotentiation of MeA-VmH and MeA-BNST synapses is time constrained. This is consistent with the finding that there is a critical period after synaptic potentiation when depotentiation can be induced (e.g., 10 min in hippocampal slices; Chen et al., 2001; Huang and Hsu, 2001). The molecular mechanism for potentiation of the $\mathrm{MeA}-\mathrm{VmH}$ and MeA-BNST synapses is an intriguing question for future studies. Neurotransmitter receptors including NMDARs, mGluRs, AMPARs, GABA-A receptors, and endocannabinoid receptors that are shown to mediate synaptic plasticity in other brain regions are potentially involved. Moreover, synaptic potentiation is often accompanied by the structural changes of synapses, such as formation and enlargement of dendritic spines, which support long-term information storage (Bolshakov et al., 1997; Toni et al., 1999; Bosch and Hayashi, 2012). Spine formation in the auditory cortex and at lateral amygdala-auditory cortex synapses has also been observed after foot shock stress (Yang et al., 2016; Lai et al., 2018). The effect of foot shock-induced aggression on the structure and formation of spines at $\mathrm{MeA}-\mathrm{VmH}$ and $\mathrm{MeA}-\mathrm{BNST}$ synapses is of interest to future studies.

\section{References}

Albert DJ, Wong RC (1978) Hyperreactivity, muricide, and intraspecific aggression in the rat produced by infusion of local anesthetic into the lateral septum or surrounding areas. J Comp Physiol Psychol 92:1062-1073.

American Psychiatric Association (2013) Diagnostic and statistical manual of mental disorders, Ed 5. Washington, DC: American Psychiatric Association.

Anthony TE, Dee N, Bernard A, Lerchner W, Heintz N, Anderson DJ (2014) Control of stress-induced persistent anxiety by an extraamygdala septohypothalamic circuit. Cell 156:522-536.

Bali A, Jaggi AS (2015) Electric foot shock stress: a useful tool in neuropsychiatric studies. Rev Neurosci 26:655-677.

Blanchard RJ, Blanchard DC (1977) Aggressive behavior in the rat. Behav Biol 21:197-224.

Bolshakov VY, Golan H, Kandel ER, Siegelbaum SA (1997) Recruitment of new sites of synaptic transmission during the cAMP-dependent late phase of LTP at CA3-CA1 synapses in the hippocampus. Neuron 19:635-651.

Bosch M, Hayashi Y (2012) Structural plasticity of dendritic spines. Curr Opin Neurobiol 22:383-388.

Bourin M, Hascoët M (2003) The mouse light/dark box test. Eur J Pharmacol 463:55-65.

Brivio E, Lopez JP, Chen A (2020) Sex differences: transcriptional signatures of stress exposure in male and female brains. Genes Brain Behav 19:e12643.

Bubak AN, Watt MJ, Renner KJ, Luman AA, Costabile JD, Sanders EJ, Grace JL, Swallow JG (2019) Sex differences in aggression: differential roles of 5-HT2, neuropeptide F and tachykinin. PLoS One 14:e0203980.

Butler CW, Wilson YM, Gunnersen JM, Murphy M (2015) Tracking the fear memory engram: discrete populations of neurons within amygdala, hypothalamus, and lateral septum are specifically activated by auditory fear conditioning. Learn Mem 22:370-384.

Can A, Dao DT, Arad M, Terrillion CE, Piantadosi SC, Gould TD (2012) The mouse forced swim test. J Vis Exp (59):3638.

Canteras NS, Simerly RB, Swanson LW (1995) Organization of projections from the medial nucleus of the amygdala: a PHAL study in the rat. J Comp Neurol 360:213-245.

Chang $\mathrm{CH}$, Gean PW (2019) The ventral hippocampus controls stress-provoked impulsive aggression through the ventromedial hypothalamus in post-weaning social isolation mice. Cell Rep 28:1195-1205.e3.

Chang CH, Hsiao YH, Chen YW, Yu YJ, Gean PW (2015) Social isolation-induced increase in NMDA receptors in the hippocampus exacerbates emotional dysregulation in mice. Hippocampus 25:474485.

Chang CH, Su CL, Gean PW (2018) Mechanism underlying NMDA blockade-induced inhibition of aggression in post-weaning socially isolated mice. Neuropharmacology 143:95-105.

Chen YL, Huang CC, Hsu KS (2001) Time-dependent reversal of long-term potentiation by low-frequency stimulation at the hippocampal mossy fiber-CA3 synapses. J Neurosci 21:3705-3714.

Coolen LM, Wood RI (1998) Bidirectional connections of the medial amygdaloid nucleus in the Syrian hamster brain: simultaneous anterograde and retrograde tract tracing. J Comp Neurol 399:189209.

Crawley JN (1999) Behavioral phenotyping of transgenic and knockout mice: experimental design and evaluation of general health, sensory functions, motor abilities, and specific behavioral tests. Brain Res 835:18-26.

Davis M, Walker DL, Miles L, Grillon C (2010) Phasic vs sustained fear in rats and humans: role of the extended amygdala in fear vs anxiety. Neuropsychopharmacology 35:105-135.

Dennis M (1976) VMH lesions and reactivity to electric footshock in the rat: the effect of early testosterone level. Physiol Behav 17:645-649. 
Dorfman HM, Meyer-Lindenberg A, Buckholtz JW (2014) Neurobiological mechanisms for impulsive-aggression: the role of MAOA. Curr Top Behav Neurosci 17:297-313.

Falkner AL, Dollar P, Perona P, Anderson DJ, Lin D (2014) Decoding ventromedial hypothalamic neural activity during male mouse aggression. J Neurosci 34:5971-5984.

Glangetas C, Girard D, Groc L, Marsicano G, Chaouloff F, Georges F (2013) Stress switches cannabinoid type-1 (CB1) receptor-dependent plasticity from LTD to LTP in the bed nucleus of the stria terminalis. J Neurosci 33:19657-19663.

Gluck JP, Sackett GP (1974) Frustration and self-aggression in social isolate rhesus monkeys. J Abnorm Psychol 83:331-334.

Golden SA, Heshmati M, Flanigan M, Christoffel DJ, Guise K, Pfau ML, Aleyasin H, Menard C, Zhang H, Hodes GE, Bregman D, Khibnik L, Tai J, Rebusi N, Krawitz B, Chaudhury D, Walsh JJ, Han MH, Shapiro ML, Russo SJ (2016) Basal forebrain projections to the lateral habenula modulate aggression reward. Nature 534:688-692.

Gomez DM, Newman SW (1992) Differential projections of the anterior and posterior regions of the medial amygdaloid nucleus in the Syrian hamster. J Comp Neurol 317:195-218.

Goodson JL, Evans AK, Soma KK (2005) Neural responses to aggressive challenge correlate with behavior in nonbreeding sparrows. Neuroreport 16:1719-1723.

Haller J, Tóth M, Halasz J, De Boer SF (2006) Patterns of violent aggression-induced brain c-fos expression in male mice selected for aggressiveness. Physiol Behav 88:173-182.

Hascoët M, Bourin M (1998) A new approach to the light/dark test procedure in mice. Pharmacol Biochem Behav 60:645-653.

Hashikawa K, Hashikawa Y, Falkner A, Lin D (2016) The neural circuits of mating and fighting in male mice. Curr Opin Neurobiol 38:27-37.

Hashikawa Y, Hashikawa K, Falkner AL, Lin D (2017) Ventromedial hypothalamus and the generation of aggression. Front Syst Neurosci 11:94.

Hodges TE, Louth EL, Bailey CDC, McCormick CM (2019) Adolescent social instability stress alters markers of synaptic plasticity and dendritic structure in the medial amygdala and lateral septum in male rats. Brain Struct Funct 224:643-659.

Hong W, Kim DW, Anderson DJ (2014) Antagonistic control of social versus repetitive self-grooming behaviors by separable amygdala neuronal subsets. Cell 158:1348-1361.

Huang CC, Hsu KS (2001) Progress in understanding the factors regulating reversibility of long-term potentiation. Rev Neurosci 12:5168.

Jennings JH, Sparta DR, Stamatakis AM, Ung RL, Pleil KE, Kash TL, Stuber GD (2013) Distinct extended amygdala circuits for divergent motivational states. Nature 496:224-228.

Kaidanovich-Beilin O, Lipina T, Vukobradovic I, Roder J, Woodgett JR (2011) Assessment of social interaction behaviors. J Vis Exp (48):2473.

Kim SY, Adhikari A, Lee SY, Marshel JH, Kim CK, Mallory CS, Lo M, Pak S, Mattis J, Lim BK, Malenka RC, Warden MR, Neve R, Tye KM, Deisseroth K (2013) Diverging neural pathways assemble a behavioural state from separable features in anxiety. Nature 496:219-223.

Koolhaas JM, Coppens CM, de Boer SF, Buwalda B, Meerlo P, Timmermans PJ (2013) The resident-intruder paradigm: a standardized test for aggression, violence and social stress. J Vis Exp (77):4367.

Kruk MR, Van der Poel AM, Meelis W, Hermans J, Mostert PG, Mos $J$, Lohman AH (1983) Discriminant analysis of the localization of aggression-inducing electrode placements in the hypothalamus of male rats. Brain Res 260:61-79.

Lai CSW, Adler A, Gan WB (2018) Fear extinction reverses dendritic spine formation induced by fear conditioning in the mouse auditory cortex. Proc Natl Acad Sci USA 115:9306-9311.

Lammers JH, Kruk MR, Meelis W, van der Poel AM (1988) Hypothalamic substrates for brain stimulation-induced attack, teeth-chattering and social grooming in the rat. Brain Res 449:311-327.

Lee G, Gammie SC (2009) GABA(A) receptor signaling in the lateral septum regulates maternal aggression in mice. Behav Neurosci 123:1169-1177.

Lee G, Gammie SC (2010) GABAA receptor signaling in caudal periaqueductal gray regulates maternal aggression and maternal care in mice. Behav Brain Res 213:230-237.

Lee H, Kim DW, Remedios R, Anthony TE, Chang A, Madisen L, Zeng H, Anderson DJ (2014) Scalable control of mounting and attack by Esr1+ neurons in the ventromedial hypothalamus. Nature 509:627-632.

Lin D, Boyle MP, Dollar P, Lee H, Lein ES, Perona P, Anderson DJ (2011) Functional identification of an aggression locus in the mouse hypothalamus. Nature 470:221-226.

Márquez C, Poirier GL, Cordero MI, Larsen MH, Groner A, Marquis J, Magistretti PJ, Trono D, Sandi C (2013) Peripuberty stress leads to abnormal aggression, altered amygdala and orbitofrontal reactivity and increased prefrontal MAOA gene expression. Transl Psychiatry 3:e216.

Masugi-Tokita M, Flor PJ, Kawata M (2016) Metabotropic glutamate receptor subtype 7 in the bed nucleus of the stria terminalis is essential for intermale aggression. Neuropsychopharmacology 41:726-735.

McCue MG, LeDoux JE, Cain CK (2014) Medial amygdala lesions selectively block aversive pavlovian-instrumental transfer in rats. Front Behav Neurosci 8:329.

McHugh T, Forbes D, Bates G, Hopwood M, Creamer M (2012) Anger in PTSD: is there a need for a concept of PTSD-related posttraumatic anger? Clin Psychol Rev 32:93-104.

Miczek KA, Faccidomo S, De Almeida RM, Bannai M, Fish EW, Debold JF (2004) Escalated aggressive behavior: new pharmacotherapeutic approaches and opportunities. Ann NY Acad Sci 1036:336-355.

Miczek KA, de Boer SF, Haller J (2013) Excessive aggression as model of violence: a critical evaluation of current preclinical methods. Psychopharmacology (Berl) 226:445-458.

Miller SM, Marcotulli D, Shen A, Zweifel LS (2019) Divergent medial amygdala projections regulate approach-avoidance conflict behavior. Nat Neurosci 22:565-575.

Mpakopoulou M, Gatos H, Brotis A, Paterakis KN, Fountas KN (2008) Stereotactic amygdalotomy in the management of severe aggressive behavioral disorders. Neurosurg Focus 25:E6.

Müller M, Fendt M (2006) Temporary inactivation of the medial and basolateral amygdala differentially affects TMT-induced fear behavior in rats. Behav Brain Res 167:57-62.

Nabavi S, Fox R, Proulx CD, Lin JY, Tsien RY, Malinow R (2014) Engineering a memory with LTD and LTP. Nature 511:348-352.

Nelson RJ (2006) Biology of aggression. Oxford: Oxford University Press.

Nelson RJ, Trainor BC (2007) Neural mechanisms of aggression. Nat Rev Neurosci 8:536-546.

Nikulina EM, Covington HE 3rd, Ganschow L, Hammer RP Jr., Miczek KA (2004) Long-term behavioral and neuronal cross-sensitization to amphetamine induced by repeated brief social defeat stress: Fos in the ventral tegmental area and amygdala. Neuroscience 123:857-865.

O'Donnell V, Blanchard RJ, Blanchard DC (1981) Mouse aggression increases after 24 hours of isolation or housing with females. Behav Neural Biol 32:89-103.

Padilla SL, Quu J, Soden ME, Sanz E, Nestor CC, Barker FD, Quintana A, Zweifel LS, Rønnekleiv OK, Kelly MJ, Palmiter RD (2016) Agouti-related peptide neural circuits mediate adaptive behaviors in the starved state. Nat Neurosci 19:734-741.

Porsolt RD, Bertin A, Jalfre M (1977) Behavioral despair in mice: a primary screening test for antidepressants. Arch Int Pharmacodyn Ther 229:327-336.

Potegal M, Hebert M, DeCoster M, Meyerhoff JL (1996a) Brief, highfrequency stimulation of the corticomedial amygdala induces a 
delayed and prolonged increase of aggressiveness in male Syrian golden hamsters. Behav Neurosci 110:401-412.

Potegal M, Ferris CF, Hebert M, Meyerhoff J, Skaredoff L (1996b) Attack priming in female Syrian golden hamsters is associated with a c-fos-coupled process within the corticomedial amygdala. Neuroscience 75:869-880.

Puciłowski O, Płaźnik A, Kostowski W (1985) Aggressive behavior inhibition by serotonin and quipazine injected into the amygdala in the rat. Behav Neural Biol 43:58-68.

Ramirez JM, Salas C, Portavella M (1988) Offense and defense after lateral septal lesions in Columba livia. Int J Neurosci 41:241-250.

Rau V, DeCola JP, Fanselow MS (2005) Stress-induced enhancement of fear learning: an animal model of posttraumatic stress disorder. Neurosci Biobehav Rev 29:1207-1223.

Rodgers RJ (1977) The medial amygdala: serotonergic inhibition of shock-Induced aggression and pain sensitivity in rats. Aggr Behav 3:277-288.

Rodgers RJ, Cole JC (1993) Influence of social isolation, gender, strain, and prior novelty on plus-maze behaviour in mice. Physiol Behav 54:729-736.

Rosen JB, Fanselow MS, Young SL, Sitcoske M, Maren S (1998) Immediate-early gene expression in the amygdala following footshock stress and contextual fear conditioning. Brain Res 796:132142.

Shaikh MB, Brutus M, Siegel HE, Siegel A (1986) Regulation of feline aggression by the bed nucleus of stria terminalis. Brain Res Bull 16:179-182.

Siegel A, Skog D (1970) Effects of electrical stimulation of the septum upon attack behavior elicited from the hypothalamus in the cat. Brain Res 23:371-380.

Silva BA, Mattucci C, Krzywkowski P, Murana E, Illarionova A, Grinevich V, Canteras NS, Ragozzino D, Gross CT (2013) Independent hypothalamic circuits for social and predator fear. Nat Neurosci 16:1731-1733.

Silverman JL, Yang M, Lord C, Crawley JN (2010) Behavioural phenotyping assays for mouse models of autism. Nat Rev Neurosci 11:490-502.

Smerin S, Chen A, Li H (2016) Neurophysiology of aggression in posttraumatic stress disorder. J Psychiatry 19.

Taft CT, Creech SK, Murphy CM (2017) Anger and aggression in PTSD. Curr Opin Psychol 14:67-71.

Takahashi LK, Hubbard DT, Lee I, Dar Y, Sipes SM (2007) Predator odor-induced conditioned fear involves the basolateral and medial amygdala. Behav Neurosci 121:100-110.
Todd WD, Fenselau H, Wang JL, Zhang R, Machado NL, Venner A, Broadhurst RY, Kaur S, Lynagh T, Olson DP, Lowell BB, Fuller PM, Saper CB (2018) A hypothalamic circuit for the circadian control of aggression. Nat Neurosci 21:717-724.

Tolin DF, Foa EB (2006) Sex differences in trauma and posttraumatic stress disorder: a quantitative review of 25 years of research. Psychol Bull 132:959-992.

Toni N, Buchs PA, Nikonenko I, Bron CR, Muller D (1999) LTP promotes formation of multiple spine synapses between a single axon terminal and a dendrite. Nature 402:421-425.

Toth M, Mikics E, Tulogdi A, Aliczki M, Haller J (2011) Post-weaning social isolation induces abnormal forms of aggression in conjunction with increased glucocorticoid and autonomic stress responses. Horm Behav 60:28-36.

Twining RC, Vantrease JE, Love S, Padival M, Rosenkranz JA (2017) An intra-amygdala circuit specifically regulates social fear learning. Nat Neurosci 20:459-469.

Veenema AH (2009) Early life stress, the development of aggression and neuroendocrine and neurobiological correlates: what can we learn from animal models? Front Neuroendocrinol 30:497-518.

Wong LC, Wang L, D'Amour JA, Yumita T, Chen GH, Yamaguchi T, Chang BC, Bernstein H, You XD, Feng JE, Froemke RC, Lin DY (2016) Effective modulation of male aggression through lateral septum to medial hypothalamus projection. Curr Biol 26:593-604.

Xiong Q, Znamenskiy P, Zador AM (2015) Selective corticostriatal plasticity during acquisition of an auditory discrimination task. Nature 521:348-351.

Yang CF, Chiang MC, Gray DC, Prabhakaran M, Alvarado M, Juntti SA, Unger EK, Wells JA, Shah NM (2013) Sexually dimorphic neurons in the ventromedial hypothalamus govern mating in both sexes and aggression in males. Cell 153:896-909.

Yang Y, Liu DQ, Huang W, Deng J, Sun Y, Zuo Y, Poo MM (2016) Selective synaptic remodeling of amygdalocortical connections associated with fear memory. Nat Neurosci 19:1348-1355.

Zelikowsky M, Hui M, Karigo T, Choe A, Yang B, Blanco MR, Beadle K, Gradinaru V, Deverman BE, Anderson DJ (2018) The neuropeptide Tac2 controls a distributed brain state induced by chronic social isolation stress. Cell 173:1265-1279.e9.

Zhou T, Zhu H, Fan Z, Wang F, Chen Y, Liang H, Yang Z, Zhang L, Lin L, Zhan Y, Wang Z, Hu H (2017) History of winning remodels thalamo-PFC circuit to reinforce social dominance. Science 357:162-168. 